\title{
DE LA RETÓRICA A LA ERÍSTICA EN LA INDUSTRIA EDITORIAL Y EN EL FOLLETÍN: MARÍA, LA HIJA DE UN JORNALERO DE AYGUALS DE IZCO
}

"From Rethoric to Eristic in the publishing industry and the serialized novels: Mary, or a Day laborer's Daughter, by Ayguals de Izco"

\section{Resumen}

El gran éxito de María..., debe mucho al hecho de que su autor era propietario del primer y mayor trust editorial español especializado en folletines. Gran estratega comercial, adula al pueblo, recrea acontecimientos históricos de 1833-1837 y desarrolla su ideología populista. Analizamos el paso de la retórica a la erística que persigue convencer y vender. Palabras clave: Empresa editorial, erística, Marx, Schopenhauer, Sociedad secreta.

\begin{abstract}
Mary was the most successful serial novel published in Spain in the XIX century, because its author was also owner of an important Publishing Group. This novel describes the plight of the urban working classes and the Spain's History from 1834 to 1837 as a literary device to pursue of his political ideology. This essay analizes Ayguals method, according to Schopenhauer, Eristic Dialectic.
\end{abstract}

Key words: Publishing Group, Eristic, Marx, Schopenhauer, Secret Society.

\section{PANORAMA LITERARIO Y EDITORIAL: LA SOCIEDAD LITERARIA}

Habida cuenta de la escasa exigencia artística del folletín, uno de los motivos fundamentales del especialista para aproximarse a él es su impacto social y su gran alcance popular que, en este caso, tuvo mucho que ver con la modernización que la industria editorial de nuestro país inició durante la primera mitad del s. XIX. Aunque con cierto retraso respecto a otros países europeos, es entonces cuando aumenta significativamente el número de lectores y de consumo de libros. El éxito de las novelas por entregas está relacionado con una oferta editorial que se adapta al elevado número de analfabetos (casi el 70\% de la población, un 60\% en los medios urbanos), lo cual provoca, además una situación de "continua guerra" por conseguir y mantener la clientela (Aubert, 2005: 76). Esa guerra comercial, sumada a la ideológica, provocará la transformación de la retórica en sofística y erística; lo cual deja notables huellas en el producto, es decir, en la novela, como veremos más adelante.

1 Universidad CEU San Pablo. Correo: anvar.ihum@ceu.es. Recibido: 17-02-2014. Aceptado: 16-12-2014

2 Este trabajo es resultado de la investigación realizada como parte del Proyecto "Retórica y ficción narrativa de la Ilustración a los Romanticismos (en las literaturas española, francesa, inglesa y alemana)", subvencionado por el Ministerio de Economía y Competitividad. REF.: FFI2012-35734. 
El desarrollo de esta empresa es posible por el aumento de lectores, pero también, de oyentes del texto, dadas las prácticas de lectura del momento que raramente eran un hecho individual, solitario y silencioso. Como describe Botrel, la forma de lectura dominante en este siglo era la colectiva y oralizada en voz alta, a través de la mediación del maestro, del clérigo, del pretendiente, del padre, de la madre, del encargado a tal fin en la fábrica, o del vecino. Como se señala en los tratados de la época, existían unos requisitos necesarios para dominar el "arte dificilísimo" de la lectura en voz alta. Se hacían lecturas colectivas durante las veladas en sociedad o en veladas del mundo rural, en gabinetes de lectura programados semanalmente, en centros políticos, en casinos o en talleres, mientras trabajaban los operarios (Botrel, 1998: 577-590). Los periódicos y las novelas por entregas eran frecuente objeto de lectura colectiva, como recogen muchas novelas de la época, plasmando el gusto español por oír dichos textos. Y como es obvio, dicha lectura en voz alta, privada o pública, dramatizada o interpretada por un intermediario, también deja señas retóricas en el texto.

Respecto al asunto novelesco, los folletines se caracterizarán por un gusto popular poco sofisticado y adaptado a la demanda comercial: Una trama poco verosímil, enrevesada y muchas veces absurda, un acusado sentimentalismo, la escasa o nula psicología de los personajes, el maniqueísmo buenos/malos, o la temática amorosa, a veces entreverada por episodios misteriosos, lo cual es propio del subgénero de las ligas secretas. Todo ello lo encontramos en el caso de María. Estos rasgos del folletín extendieron el deseo de leer entre la clase popular, lo cual convirtió al libro en un verdadero producto comercial.

Dichos elementos característicos de la novela folletinesca, paradójicamente, coadyuvaron al nacimiento de la gran novela realista, como diversos especialistas han estudiado. J. F. Montesinos (1955) vinculó la frustración de la modernidad española a la lenta gestación de la novela en nuestro país, pues, tras su alumbramiento en el siglo XVII, el género se vio desprestigiado en las poéticas neoclásicas por su falta de alcurnia clásica. A este desprestigio, se sumaba la "manía moralizadora" que juzgaba la novela como ilusión peligrosa a causa de las costumbres a veces viciosas que reflejaba.

Por eso, el expansionismo editorial francés fue fundamental en España: los autores galos comenzaron a ser traducidos e imitados y la industria editorial nacional protagonizó un despertar a partir de 1815-20, tomando del país vecino nuevos métodos de difusión y venta, como sus gabinetes de lectura, las suscripciones o las publicaciones por entregas, que popularizaron el género novelístico. El lector español demandaba novelas históricas a lo Walter Scott, folletines históricos tipo Dumas o folletines sociales, tipo Sue; lo cual, andando el tiempo, condujo a la demanda de novelas de costumbres contemporáneas a lo Balzac. Además de novelas, también los periódicos eran leídos en voz alta $^{3}$, difundiéndose el gusto por la descripción costumbrista, género que también contribuyó a aproximar el gusto lector español a la novela realista, y a la vez, entorpeció

3 Sabemos, por ejemplo que entre 1840-1843, aquellos días en que llegaban por correo a Zaragoza Fray Gerundio o El Huracán, se celebraban lecturas en voz alta de estos periódicos progresistas. (Botrel, 1998: 582). 
su nacimiento; lo cual, como afirma Romero Tobar (1998), puede también decirse de los otros dos géneros literarios: la novela histórica y el folletín.

En España, el gran paladín, traductor e imitador de Eugenio Sue fue Wenceslao Ayguals de Izco (1801-1875), a su vez, traducido al francés por el admirado folletinista francés a quien dedica su obra más popular: María, la hija de un jornalero. Su autor era lo que entonces se llamaba un "capitalista", si bien, simpatizante del "pueblo", por lo que sus "lacrimógenas y alcaloides novelas" son -en palabras de Calvo Carilla- "alegatos redentoristas" (2008:145). En 1841, Ayguals había fundado junto a sus hermanos y Juan Martínez Villergas su propia editorial, La Sociedad Literaria, que hasta 1859 fue una de las más importantes en nuestro país. Dicha editorial publicaba colecciones de novelas a precios populares, bajo esa visión marcadamente humanitarista y socializante. S. Baulo describe la empresa como un verdadero trust en el que Wenceslao controlaba a los productores (autores), su producción (la obra), impresión, publicidad y recepción. A su juicio, la eficacia y modernidad de la estrategia comercial "global" de Wenceslao convierten La Sociedad Literaria en un modelo de empresa editorial (S. Baulo, 2005: 63).

Mientras sus hermanos se encargaban de los negocios en Francia y Cuba, Wenceslao llevaba exitosamente las riendas de la empresa en España, cuya principal fuente de ingresos era la venta de novelas por entregas, especialmente, éxitos como Los misterios de París y El judio errante de Sue, o María, la hija de un jornalero. También en las mismas fechas en que publica estas y otras novelas por entregas, se encargó de la dirección y fundación de varios periódicos de dicha editorial, caracterizados por el tono políticosatírico: La Risa, Guindilla, La Carcajada, El Fandango o El Dómine Lucas (Sánchez García, 2001: 127-129). Wenceslao promocionaba sus productos literarios desde sus propios periódicos, por lo que en las páginas de estos dos últimos se hizo una campaña especialmente intensa de promoción de María: seis meses antes de iniciarse la venta de sus entregas ya había recibido elogios en artículos críticos, que por supuesto, continuaron durante su publicación. Además, ideológicamente, novela y periódicos se retroalimentaban. El furibundo anticlericalismo y populismo de El Dómine Lucas, o la atribución de conspiraciones y males políticos a una tenebrosa sociedad secreta apostólica denominada Ángel Exterminador, alimentaban el deseo de compra de la futura novela en que se prometía hacer revelaciones interesantísimas sobre el modo

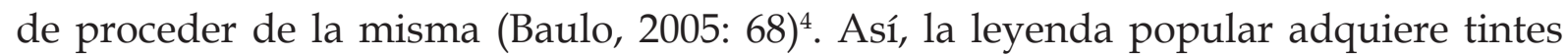
aparentes de historicidad. Ese afán comercial tiene consecuencias directas no sólo en la forma de la novela, sino en su fondo. Por ello, Botrel hablaba de un "argumento falaz", pensado para dar al comprador lo que quiere, lo cual produce una interesante "unidad de creación y consumo" (Botrel, 1974).

4 Baulo estudia la estrategia comercial pormenorizadamente: el lenguaje hiperbólico para describir los "magníficos grabados de inusitado lujo", el sistema de suscripción, la supuesta "ganga" de cada entrega (que sumando los dos reales de cada una de las 54 entregas es un precio realmente elevado), los "suntuosos" regalos al comprador al terminar cada tomo (jun grabado en acero del propio autor!), o las noticias propagandísticas disculpándose por haber agotado "todo" el papel de la fábrica de Burgos y no poder imprimir más ejemplares de los 3.000 ya vendidos de la primera entrega. 
Diputado, alcalde, empresario, autor de poesía, teatro, novelas, traducciones e innumerables artículos periodísticos ${ }^{5}$, Wenceslao Ayguals de Izco era un hombre culto, que había viajado, leído y conocido a grandes autores nacionales y extranjeros. La novela que nos ocupa fue publicada por entregas entre 1845 y 1846, y para 1849 ya había sido reeditada en siete ocasiones. El mismísimo Sue la tradujo al francés en 1846, escribiéndole un elogioso prólogo, que Wenceslao rentabilizaría publicitariamente en España. El extenso título de la traducción francesa destaca lo más significativo de la obra, esa mixtura de novela ideológica-costumbrista-histórica que no renuncia a los rasgos folletinescos:

\begin{abstract}
María la española víctima de un monje. Historia de Madrid, costumbres y usos de sus habitantes, descripción de los célebres combates de toros, de edificios significativos, paseos, celebraciones; historia de los acontecimientos políticos posteriores a la promulgación del estatuto real hasta los hechos de la Granja, con importantes revelaciones relativas a la influencia ejercida en estos acontecimientos por la tenebrosa sociedad el "Ángel Exterminador" [...] (Benítez, 1979: 204-5).
\end{abstract}

En pocos años, la novela de Ayguals imita el éxito de los "misterios" de Sue por Europa: una segunda edición belga en el 1847, dos florentinas, una en Milán, otra en Oporto, otra en Lisboa, e incluso se publica en fechas semejantes otra en Sttutgart. La segunda parte de la novela, La marquesa de Bellaflor o El niño de la inclusa apareció en el mismo año en que finalizó María, continuando las vicisitudes de la protagonista, ya casada, y los episodios históricos desde la rebelión de La Granja hasta el casamiento de Isabel II. Estas aventuras fueron también éxito popular, traducidas y reeditadas aún en 1920 (en versión abreviada de la colección "La novela corta", prologada por Carmen de Burgos) y nuevamente en 1925 (por "La prensa popular"). Esta vez con menor éxito, y en la misma imprenta de su propiedad, Ayguals todavía publicó una tercera parte ideológicamente igual posicionada: El palacio de los crímenes o El pueblo y sus opresores (Benítez, 1979).

Sólo unos años después de publicar María, antes de que el autor cumpliese los cincuenta años, su amigo Blas $\mathrm{M}^{\mathrm{a}}$ Araque ya había escrito una extensa biografía sobre él -40 páginas-, publicada como parte de la campaña publicitaria por la Sociedad Literaria. Así, sabemos de su formación y contacto con los ambientes más selectos que después criticará en sus novelas, sus vicisitudes políticas como diputado y alcalde de Vinaroz, su participación en las guerras carlistas, la muerte en ella de su hermano mientras luchaba contra Cabrera, y su ascenso como "capitalista" editor y autor. Siguiendo el recurso de fingir no ser encomiástico, elogia a su amigo (y jefe) hasta lo hiperbólico, mencionando la fama internacional del escritor, su honradez política (que, dice, sólo ha sido puesta en entredicho por falaces), su patriotismo, su bizarría como comandante de la Milicia Nacional durante las guerras carlistas, sus talentos y virtudes, su genio, su comportamiento y modales... por lo que, destacando en cursiva,

5 Se ha señalado que periódicos de su editorial como La Linterna Mágica (enero de 1849-diciembre de 1850) fueron redactados casi exclusivamente por él mismo. 
escribe: "la voz general lo designa como el abogado predilecto del pueblo" (Araque, 1851: $1-2)$.

Dada la exaltación del biógrafo, el tono con que se refiere a la novela que nos ocupa lo lleva a decir que con María, Ayguals se convirtió en "el Regenerador de la novela española", puesto que, antes de él, "la novela nacional no existía". En el mismo tono publicitario se nos informa que "toda" la prensa nacional saludó a su autor con "unánimes aplausos". Según Araque, es materialmente imposible hacer la lista de todas las personalidades que ensalzaron las dotes de literato, filósofo y hombre profundo en "todos los ramos" del saber humano (1851: 23). Y aunque la exageración del amigo publicista es evidente, lo cierto es que gozaba de una enorme popularidad, y si bien no puede considerarse regenerador de la novela nacional, supone un eslabón imprescindible para llegar a ella.

\section{HISTORIA, FICCIÓN E IDEOLOGÍA}

Bajo el título de María, la hija de un jornalero figura, antes del nombre de su autor, "Historia-Novela original"; escrito así, con un guion. La dificultad de deslindar qué es ficticio y qué es histórico se produce a lo largo de toda la novela, pues el autor pasa de lo uno a lo otro constantemente, a veces descarada y torpemente, pero en algunas ocasiones, sutilmente, confundiendo leyenda popular, invención propia, detallada y verosímil, y datos y acontecimientos históricos, de tal modo que, sin darnos cuenta, podemos tomar por real lo inventado.

Teniendo en mente los ejemplos de lo primero, R. Benítez, en su extenso y profundo análisis de la obra de Ayguals, destacaba la torpeza con que Historia y ficción discurren paralelamente sin lograr la magistral fusión que Galdós alcanzará. La comparación de ambos narradores surge naturalmente ante la común selección de elementos, escenarios, acontecimientos históricos, costumbres, etc. Pero el resultado es enormemente diferente. Sin embargo, coincidiendo en el análisis general de Benítez, más torpe aún que ese discurrir no integrado sino paralelo entre la gran Historia y los acontecimientos de los personajes, es la especialmente abrupta intervención del autor en el texto para dar su opinión -fingiendo objetividad casi siempre. Peor que esos aditamentos históricos al folletín sentimental, son los aditamentos ideológicos: toscamente "incrustados" tras tres, cuatro o cinco líneas de puntos, indicándole al lector con mayúsculas las conclusiones principales que en su torpe magín debe recordar, o iniciando y terminando un capítulo íntegro. Nos encontramos páginas y páginas de datos interesantes histórica o políticamente, pero toscos excursos que hacen que el lector olvide los acontecimientos novelísticos (por otra parte, tan enrevesados que ya era difícil recordarlos).

La lectura forzadamente apresurada de sus extensos folletines ha llevado en varias ocasiones a una malinterpretación política de la doctrina que el autor expone profusamente. Próximo al socialismo utópico, se muestra vagamente humanitarista y socializante, pero sus novelas -y concretamente María- dedican extensos párrafos a defender que, lejos de la inocencia de creer que con la eliminación de la propiedad 
privada se acaban los males y la desigualdad, la propiedad acarrea beneficios sociales, los cuales expondrá en sus frecuentes digresiones. En ese sentido, Elorza -y después J.L. Calvo Carilla- es quien mayor detenimiento ha dedicado a analizar su paso desde el humanitarismo filantropista, burgués, demócrata y utópico de los primeros folletines a un vago espiritualismo humanitarista y redentorista en las últimas novelas ${ }^{6}$ (Calvo Carilla, 2008: 145). Por lo que el texto dice y el tono enardecido en que lo hace, se trata de un burgués defensor del liberalismo radical, demócrata y republicano, anticlerical, anticarlista y antiabsolutista furibundo, que por ese radicalismo, es crítico con los liberales moderados (si bien, por ejemplo, evita dar los nombres de éstos, como sucede, por ejemplo, al criticar veladamente a Martínez de la Rosa).

Siendo radical defensor de las libertades, es de notar su perspectiva de propietario burgués. Montesinos ya había señalado que por encima del objetivo ideológico de las novelas sociales, eran claros los intereses mercantiles de sus novelas por entregas, y las ideológicamente afines, traducciones de Sue (Montesinos, 1980: 93). También Benítez hace depender buena parte del posicionamiento ideológico del autor en la narración de esa tarea como editor que se debe al mercado (Benítez, 1979). Y Botrel destaca cómo el argumento sigue los intereses de sus consumidores (Botrel, 1974).

Filosófica e ideológicamente, Ayguals no ha abandonado la visión de la Historia de los ilustrados, esa "comunidad tendencial en la reacción a la realidad" que Georg Lukács verá cambiada tras la revolución de 1848 (1976: 193). En la novela que nos ocupa, el término "ilustración" aparece con frecuencia en contraposición a "clero". Ayguals se queda anclado en un redentorismo que idealiza al pueblo, y deposita toda su fe en que, aniquilado el freno clerical a la ilustración, las reformas alcanzadas con la extensión de libertades lograrán la soberanía popular. Como expone Lukács, en el periodo anterior a ese 1848, la burguesía era dirigente del desarrollo social e ideológico. Y el problema central de la actitud burguesa ante la Historia, como reconocemos en nuestro autor, es su noción de progreso. Esa ideología del progreso que, sigue Lukács, provoca la "idea de la historia como evolución lisa y rectilínea" (1976: 195).

Nuestro folletín tiene un claro objetivo ideológico manifiesto a lo largo de la narración y explicitado en varias ocasiones con rotundidad. El autor se ha propuesto como objetivo prioritario propagar su anticlericalismo, que considera obstáculo del progreso en sentido humanitarista y republicano. Los personajes, las escenas, acontecimientos, descripciones y situaciones creadas persiguen dicha finalidad. Al aproximarse el final de María, la hija de un jornalero, fiel a esa interpretación filosófica de la Historia que aún cree en la idea de "progreso", castiga a los malvados y premia a los virtuosos: Mientras el furibundo Fray Patricio llora en su oscuro calabozo, traicionado por su perversa compinche, la tía Esperanza -también condenada a pena perpetua-, se atisba el feliz enlace de los enamorados, la curación de los enfermos, la recompensa de la virtud y hasta la "resurrección" de los muertos si son justos (pues milagrosamente no eran tales: hubo un error periodístico en el caso del marqués de Bellaflor y un salvamento

6 Elorza lo emparenta ideológicamente con la línea que después representarán un Castelar o Azaña, separándola del utopismo de Garrido o Cámara. El mismo crítico señala que Ayguals utiliza el término "socialista" como insulto. 
in extremis de la suicida María, ya restaurado su honor). Por ello, el autor escribe "Así vendrá también un día de justicia y de espiacion para los malvados que se empeñan en arrebatarnos las instituciones liberales" (sic, 1847: 329).

Ayguals de Izco sintetiza en todo ello los esfuerzos concentrados en su obra, reconociendo la erística de su composición, es decir, la utilización de todo recurso que le permita "quedarse con la razón". En este extenso párrafo (de una sola frase) se ufana de haber tramado una novela con que argumentar su postura ideológica como respuesta a la de quienes se han impuesto en las discusiones políticas. Por eso, su retórica apela a cualquier recurso, para poder enfrentarse a quienes públicamente parecen briosos vencedores de la discusión, pero él considera fanáticos. Es decir, el folletín da voz al pueblo que lo compra; lo escrito es su respuesta, dirigida a sus adeptos y pública respuesta erística:

\begin{abstract}
Retratar en fray Patricio a la inmunda pandilla inquisitorial que aun aspira al dominio de España, presentarla á la faz del mundo con todos los horrores de su deformidad, he aquí el objeto primordial de nuestro trabajo; he aquí el gran pensamiento para cuyo desarrollo hemos apelado a todos los recursos, a todas las fuerzas de nuestra escasa inteligencia, porque si en toda ocasión es útil y conveniente que conozca el pueblo los medios de que se vale la astuta hipocresía para ocultar sus infames designios, sus miras de absoluto predominio, nunca más que ahora es deber de los amantes de la ilustración y de la dignidad española, hacer resonar por do quiera con enérgica valentía el acento del honor, la voz de la justicia, el eco potente de la verdad, para confundir y anonadar á esos frenéticos apóstoles del absolutismo, que merced al sistema reaccionario que desde el entronizamiento de las sublimes inteligencias domina en España, han tomado tales bríos en el palenque de la discusión, que osan presentarse como los únicos adalides dignos de ceñir el lauro de la victoria (negrita mía, 329).
\end{abstract}

Ayguals aborrece con todas sus fuerzas la causa carlista, contra la que luchó no sólo políticamente sino también militarmente. Por ejemplo, respecto al posible matrimonio de Isabel II con el conde de Montemolín, entiende que ahora le corresponde luchar con la esgrima retórica: "Los amigos de la inquisición, de las horcas y de los frailes, han apelado a extravagantes sofismas y haciendo de la cuestión del matrimonio una cuestión dinástica" (1847: 330). Siendo correcta la forma del silogismo, la materia es pura especulación y por tanto, erística, pues afirma que los carlistas son amigos de la Inquisición, ya desaparecida, pero que la novela ha descrito cómo aún viva, misteriosamente escondida y personalizada en la invención del personaje de Patricio y de la históricamente inexistente sociedad secreta del Ángel Exterminador ${ }^{7}$. Asimismo, los carlistas, dice, son amigos de las horcas, generalización que en época de guerras parece aplicable a ambos contendientes. Y por último, los carlistas son amigos de los frailes, entendiendo como frailes a esos personajes rijosos, comilones, crueles, violadores, perseguidores de virtuosas como María, conspiradores y etc. Aun habiendo

7 He de reconocer que una vez redactado este artículo, al reflexionar sobre los medios retóricos y materiales de Ayguals y el éxito de su novela me pareció que los hechos conducían a la hipótesis que luego he visto confirmada: el escritor era masón. De él escribió Pío Baroja que era un "masón muy activo y entusiasta de la escenografía del triángulo y de la escuadra, tipo pequeño, barbudo y un poco ridículo" (2008: 673). Su nombre se encontraba en una lista de trescientos integrantes del El Gran Oriente. Así pues la novela en sí misma sigue la estrategia de que "la mejor defensa es el ataque". 
dejado de ser fraile al comienzo de la novela su personaje, siempre se hará referencia a él como Fray Patricio. Lo cual es inexacto históricamente, pues exclaustrado y dedicado a "negocios" como el proxenetismo, "conspiraciones" políticas y otras turbias ocupaciones, tal tratamiento no le correspondía en la mayoría de las páginas de la novela.

\section{EL PELIGRO DE LAS CONSTRUCCIONES ESPECULATIVAS}

Con fines comerciales, tanto la prensa de La Sociedad Literaria como la propia novela repetían que se harían "interesantes revelaciones" sobre la sociedad secreta compuesta de sacerdotes absolutistas que privaban de su libertad y derechos al pueblo. El lector moderno conocedor de la Historia, ahora sabe que la interpretación de los acontecimientos que lee en la novela son pura invención que aprovechaba la leyenda popular y especulaba sobre su imaginaria participación en acontecimientos históricos pasados y presentes. El autor se sirve del texto para propagar su ideología y adoctrinar al pueblo, ahora bien, aunque subtitule su obra "Historia-novela" le está presentando un enemigo inventado. Siguiendo la argumentación implícita en la novela de Ayguals, una vez desaparecido el Ángel Exterminador (el clero), el pueblo obtendría todos los derechos que se le robaban por medio de las reformas propuestas. Sin embargo, aquello que se nos presenta como conspiración impenetrable, dominio absoluto, sempiterno y etéreo no puede ser eliminado. Es decir, no hay modo de enfrentarse a la privación de derechos por parte del Estado y de la sociedad, tal y como los folletinistas lo presentan, reduciéndolo a "misterios" y "secretos". La crítica de Marx y Engels a este tipo de literatura y a sus falaces recursos no se hizo esperar, y es probable que autores como Ayguals la conocieran muy pronto.

Benito Hortelano habla en sus Memorias de su amistad con Ayguals durante aquellos años (1936: 21). Como su amigo, Hortelano era periodista, editor e impresor de folletines. En el mismo año 1846, apareció en su Sociedad Tipográfica una anónima defensa de los folletines: De la Novela-Folletín. Su origen, progresos e influencia social. Este interesantísimo opúsculo comienza renegando de la crítica que Marx hacía a los folletines en La sagrada familia: "No es sólo el espíritu especulador de nuestra época, como ha sentado con sobrada ligereza algún crítico, el que ha generalizado en todas las clases el gusto á este género de leyendas" (Anónimo, 1846: 1). El anónimo autor, niega sin argumentar, la acusación que la obra de Marx, de 1845, ha hecho a los folletines y subraya la trascendencia de engalanar con todos los atractivos del arte y todos los encantos de la ilustración las ideas políticas para hacer la novela "persuasiva y convincente en su fondo, bella en su estilo, vigorosa y animada en sus pinturas, amena y palpitante en sus cuadros, verídica en su narración, juiciosa en sus raciocinios, moral en su doctrina y elocuente a la par que poderosa en sus argumentos"' (Anónimo, 1846: 9). Así, repite elogios a Sue, críticas al clero, hace una larga lista de desmanes jesuíticos y expone ideas semejantes a las defendidas por Ayguals en el folletín recién aparecido. Fiel a esa idea de progreso, el anónimo autor a quien Hortelano publica, considera los folletines instrumentos eficaces en la lucha contra las "maquinaciones de los que 
trabajan incansables por hacer retrogadar al mundo al estado de abyección de los siglos pasados" (Anónimo, 1846: 9).

Pero el interés y crítica de Marx a los folletines se basa en la razón, no en el deseo, pues preludia ese cambio en la interpretación de la Historia del que Luckács hablará. El interés del filósofo por Los misterios de París y la literatura folletinesca puede parecer sorprendente en el momento actual, pero su extensa crítica a la obra y género de Sue, además de sentar las bases de lo criticable de la obra de Ayguals de Izco, es lógica respuesta al idealismo de los jóvenes hegelianos y de ese "opio del pueblo" de la fe en el advenimiento del progreso como fuerza operante en la Historia, de una manera casi sobrenatural.

Por eso, en referencia a lo especulativo de estos folletines histórico-sociales-políticos hace "crítica crítica mercader de misterios". Es decir, Marx ve en ellos construcciones especulativas con una finalidad comercial, por lo que se burla de lo supuestamente misterioso que rodea lo social, lo religioso, lo mundano, la justicia o los derechos (según la novela de Sue y perfectamente aplicable a la novela española). Resumiendo capítulos enteros de La sagrada familia, el folletín repite constantemente deducciones del autor, que en su representación novelística se convierten en lo esencial. De esto, explica el filósofo, surge un nuevo "misticismo", porque queriendo renunciar a lo abstracto, "tiene aires de no renunciar a ello". Marx critica del folletín que "se eleva en sus deducciones a la región crítica del cielo" y se burla de la que denomina "teoría criminalista celeste" de estas novelas, por la que se castiga a los malos y se premia a los buenos en la tierra, anticipando la sentencia divina (1981: 207). Los "misterios" de Sue, como el Ángel Exterminador de Ayguals o el modo de vivir que atribuye a políticos, clérigos o aristócratas, e incluso a ese abstracto "pueblo" idealizado, surgen del "éter" del "cerebro" de sus autores, "y no de la tierra material". Así -sigue Marx-, el escritor, "transforma al misterio en sujeto autónomo que se encarna en condiciones y personas reales, y que se manifiesta en condesas, marqueses, grisetas, porteros, notarios, charlatanes, así como en intrigas de amor, bailes, puertas de madera, etc" (1981: 75). De tal modo que "el lector toma a la especulación por la realidad y a la realidad por la especulación”. Por eso, el interés central de Marx es demostrar esa especulación, ironizando, además, constantemente sobre el estilo con que están escritas estas novelas. A su juicio, el autor de folletines es ridículo simplificador de la complejidad de asuntos, gentes o situaciones, pues "construye verdaderas personas ideales", por lo que es necesario tener la misma simplicidad mental que atribuye al autor, para creer en las generalizaciones y estereotipos, ángeles o demonios que nada tienen de carne y hueso. La identificación de salones aristocráticos y ambiente prostibulario, la idealización del protagonista masculino, aristócrata amigo del pueblo, los cubiles criminales, las danzas de la corte , la devoción y honestidad de la protagonista o el redentorismo de las mujeres, son todos ellos elementos y escenas que Ayguals reproduce tomándolos de Sue; elementos irónicamente ridiculizados por un Marx que prefiere la realidad de Balzac a la nefasta influencia de las "invenciones repugnantes de la musa socialista de Eugenio Sue" (1981: 69). 


\section{RETÓRICA, SOFÍSTICA Y ERÍSTICA DEL FOLLETÍN}

En consonancia con la construcción especulativa, asistimos al proceso de abandono de una retórica que pretende la búsqueda de la verdad para pasar a ser erística y silogística, es decir, ganar adeptos y compradores, además de afianzar a los que ya lo son, al margen de la ética intelectual. Este fenómeno es el que Schopenhauer describe en su Dialéctica Erística, consciente de que la verdad objetiva de una tesis y su validez en la aprobación de los oyentes o lectores son dos cosas distintas. Quien discute -sigue Schopenhauer- no lucha por amor a la verdad, sino por su tesis (2007: 47-48). Schopenhauer reacciona contra la dialéctica idealista de Hegel, basada en que la razón es el principio fundamental, para ofrecer lo que denomina "maniobras" o "estratagemas" con que lograr el triunfo en los debates.

Es el mismo proceso al que asistimos en la novelística: en aras de la venta y de la propaganda, argumento y forma se adaptan al medio, y teniendo en cuenta el hábito de las lecturas en voz alta, no es de extrañar la semejanza con los exaltados artículos políticos de los periódicos, que también se acostumbraban a leer así. Con fines persuasivos, Ayguals hace uso de cuanto recurso retórico, erístico o silogístico le sirva para:

abogar por las clases menesterosas, realzar sus virtudes, presentar el vicio en toda su deformidad, ora se oculte haraposo en hediondas cavernas, ora ostente bordados y condecoraciones en los salones del gran mundo, ora vista sacrílegamente la modesta túnica del salvador (1847: 5).

Es de imaginar el tono que el autor esperaba en una lectura pública para aquello que escribía en mayúsculas. Su declaración explicita de objetivos novelísticos atribuye al Arte una misión social y política prioritaria, e ideológicamente lo sitúa en el populismo. Como vemos, su técnica detallista no evita lo sórdido y parte de una visión crítica de los ricos, de los militares y del clero. Por lo que aquí declara, es claro eslabón en la evolución romántica-realista que se asemeja a la realista-naturalista: En fecha tan temprana, faltan la cobertura cientifista, la pretensión de objetividad y el determinismo filosófico para ofrecer una interpretación de la literatura que la escuela Naturalista perseguirá décadas después.

En su estudio sobre Ayguals, Benítez destaca entre los rasgos estilísticos del autor su constante interpelación al lector, su sentimentalismo, el patetismo y el humorismo (Benítez, 1979). Todo ello, acompañado de unas "elocuentes" ilustraciones que, sin ser caricaturas, abultan rasgos, exageran gestos y consignan lo hiperbólico y efectista de lo relatado, el dolor de las víctimas -María y su familia-, y la perversión de los malvados -el clero, la marquesa, los absolutistas...

En comparación con las ilustraciones, el texto es mucho más hiperbólico ${ }^{8}$. Las generalizaciones, caricaturas, estereotipos e hipérboles pueblan el relato. No hay

$8 \quad$ Como antes indicaba, la novela se refiere constantemente al antagonista como "Fray" Patricio, por lo cual, llama aún más la atención que un mínimo de coherencia realista impide al ilustrador, Vallejo, retratarlo con hábito de monje, pues en los primeros capítulos dejó de ser fraile. 
sentimiento que no sea desgarrador o apasionado. Presenta un claro maniqueísmo que alimenta el nacionalismo antifrancés: los absolutistas son afrancesados, inquisidores, aristócratas y clérigos, físicamente feos, groseros, varios de ellos pelirrojos, y son unos privilegiados egoístas. En cambio, con los rasgos físicos de los “verdaderos" españoles, se nos describen al jornalero (miliciano, liberal y generoso), o a María (hermosísima morena de cabello, ojos grandes y oscuros y piel blanca). A D. Luis de Mendoza y a su padre se les permite ser gallardos rubios, porque son aristócratas, pero son, por supuesto, amigos del pueblo y de la milicia, liberales españolistas. Religiosamente, frente a la férrea jerarquía, carácter dominante y ritualismo del primer grupo de personajes, los segundos, además de ser más guapos, presentan una vaguísima religiosidad.

Así, la novela comienza ensañándose con los franciscanos, cuyo histórico voto de pobreza y sencillez, principia desmintiendo con una retórica convincente para esas mentes sencillas a las que aludía Marx, que se fían de especulaciones y se sienten atraídos por lo misterioso. Tras los muros del convento todo es lujo, pues es:

suntuoso y magnífico, como solían ser todos los nidos de aquellos avechuchos con faldas, a quienes la ilustración del siglo lanzó de la sociedad, donde pretendían ejercer su despótico dominio, y en la cual parece tratan nuevamente de introducirse, para mengua de la civilización europea, seguramente con no menos santas intenciones de avasallar al pueblo y saciar en él su hidrópica sed de riquezas, de placeres y de venganzas (1847: 12)

Los franciscanos son "embusteros" que dicen retirarse del mundo para orar y pasar la vida en medio de privaciones, pero en realidad, escribe, viven rodeados de "el lujo, la magnificencia, la ostentación, la plata, el oro, cuánto hay de más rico y pomposo" (1847: 14). El narrador interviene sin complejos para explicarnos que así es cómo están "afianzando el trono de su despotismo teocrático" (1847: 14). Aunque esta idea sea explícito punto de partida, el narrador conoce la eficacia de repetir constantemente este tipo de comentarios.

La enumeración de lujos, la hipérbole y la redundancia son eficaces recursos retóricos de una novela dosificada en entregas quincenales durante un año, que muchas veces era leída en voz alta para el público en talleres o en veladas de artesanos y jornaleros. De esta primera edición y entrega en que leemos este párrafo y otros semejantes, nos informa El Dómine Lucas que se agotaron los 3.000 ejemplares impresos, no hubo papel para duplicarla y muy pronto se multiplicaron las reediciones (Baulo, 2005: 68). Es indudable la eficacia propagandística de la novela y cómo Ayguals supo rentabilizar comercialmente el fanatismo.

Otro recurso constante son los contrastes. Hasta ese es el título de un capítulo en que Anselmo, el padre, es injustamente llevado al cadalso, en tanto que María vive rodeada de lujo. Al hablar del pueblo, Ayguals suele compararlo con la depravación de las costumbres de los ricos. El modo en que los honrados trabajadores se arreglan, hablan, visten, trabajan o actúan es sencillo, sincero y virtuoso, en tanto que la descripción del teatro o los salones aristocráticos ridiculiza la falsa moral, la hipocresía, 
la infidelidad, la gordura o falta de lozanía de jóvenes que mediante corsés, afeites o cualquiera que sea el método, falsean su aspecto. La honradez de la virtuosa María, que prefiere la muerte al deshonor, contrasta con el ambiente perverso de meretrices que fingen ser aristócratas para casarse con gente de alcurnia. Hasta las prostitutas, si son pobres, son víctimas, en tanto que las aristocráticas son verdugos. Así, "Las tres mil infelices operarias que en la fábrica de tabacos de Madrid, elaboran cigarros y rapé, son una prueba ostensible de la inclinación que hay en las hijas del pueblo al trabajo y a la virtud" (1847: 24). Los trabajadores son exprimidos con impuestos, que los hacen gemir "en la más espantosa indigencia", cuando "acaso" -dice, nuevamente especulando- se emplea su dinero "para transformar los palacios de corrompidos ambiciosos en orgías" (1847: 24). El "gran mundo" está lleno de "ridiculeces" llenas de presunción, “depravación y extravagancia" (1847: 152 y ss.). Dispuesto al halago del lector, Ayguals afirma incluso que "hay más ilustración en las masas populares y trabajadoras, que en las dos aristocracias que con ridículo empeño se disputan en la actualidad la primacía", escribe sobrepujando los conocimientos del pueblo español por encima de las aristocracias londinense y parisina (1847: 150).

Populista, Ayguals es firme defensor de todo lo español frente a lo extranjero. Incluso si el arquitecto de un edificio es extranjero, el edificio le parece de un gusto detestable. Desde la perspectiva artística, C. Reyero percibe el mismo maniqueísmo: se describe despreciativamente el lujo y ostentación que asocia a clero y aristocracia, en tanto que establece una conexión entre liberalismo y gusto nacional, sencillez y auténtica elegancia (2008: 478-488). Uno de los episodios más efectistas es en el que D. Luis se nos presenta como liberal demócrata discutiendo con dos franceses que niegan toda grandeza a España. Por ello, su artificioso discurso patriótico cita a Antonio Agustín, Quintiliano, Mariana, Núñez Pinciano, Vallés, el Brocense, Montano, Mariner, Vives, Cano... Sin desdeñar glorias como Voltaire, Racine o Corneille -dice a los franceses-, estos autores han aprovechado mucho de Lope, Calderón, Guillén de Castro o el Cid. Por toda respuesta al alegato españolista, el orgulloso francés, entre exclamaciones de “ipardiez!” y “¡cáspita!”, ofende al protagonista diciendo que "este es un país miserable, desmoralizado... un país de cafres!" Así es que, puesto que ser español, es ser caballero -dice el protagonista-, se ve "en la obligación" de retarlo a duelo (1847: 78-81).

El texto se llena de exclamaciones e interjecciones que, junto a las ilustraciones, cargan las tintas en las emociones y alcanzan el patetismo. La pobreza, la enfermedad, la miseria o la traición irán arrebatando la vida de varios de los hijos del honrado, pobre y leal jornalero; Luisa, la madre de María, perderá (y luego recuperará) la vista; Anselmo, muerto de hambre y enfermo, pasará injustamente por el cadalso y hasta será salvado in extremis del patíbulo; la protagonista intentará suicidarse a causa de las terribles acusaciones de las que es totalmente inocente... El sentimentalismo llega a tal extremo que un jilguero se convierte en motivo para apelar al corazón del lector, pues siendo el único consuelo de María, tiene que renunciar a él y venderlo para mantener a su familia. Aunque más apoteósico será el reencuentro con el animal, por lo visto, capaz de entender todo lo que su ama dice y siente $(1847: 35,38)$. 


\section{La erística o técnica de la discordia}

Lejos de la objetividad que algunos narradores ya han puesto en práctica en otros países, lo más notable es el decidido deseo de Ayguals de Izco de instigar, de provocar y enardecer al lector. En este sentido, cualquier recurso parece válido. Por ello, resulta oportuno analizar la técnica de Eris: el arte o procedimiento de la Discordia, el arte del conflicto y del debate. Hesiodo distinguía dos tipos de Discordia: una que lograba sacar lo mejor de los hombres al hacerlos competir, y otra malvada que "engendra la guerra funesta y disputa" (1990: 70). Ayguals se sitúa ideológicamente en un fanatismo que pretende aumentar la discordia, fomentar la batalla y el enfrentamiento sin ahorrar los insultos y falacias contra el adversario ideológico, en quien no admite virtudes, pues todas están monopolizadas por quienes comparten su radicalismo liberal y populista. El pueblo es honrado, digno, leal y virtuoso, aunque pobre; y el clero y demás opresores militares y aristócratas son viciosos, despóticos y usurpadores de los derechos de los menesterosos. Sólo se salvan la Milicia urbana y algunos privilegiados simpatizantes de la aristocracia o burguesía -como el propio autor. Aunque hay en la alta sociedad ejemplos de virtud, si el criminal pertenece a la alta sociedad se le respeta, pero, para enardecer al lector, le recuerda que si es del pueblo "se le desprecia y escupe!!!" (1847: 24)

Aristóteles distingue los silogismos en lógicos y dialécticos y, después -escribe Schopenhauer- en erísticos (en los que la forma del silogismo es correcta pero las proposiciones, la materia, no lo son, sino lo parecen) y sofísticos (en que es la forma del silogismo la falsa con apariencia de correcta). Pero el filósofo señala que hemos de hablar de dialéctica erística cuando no se atiende a la verdad objetiva, cuando sólo se atiende a la apariencia y al hecho de "quedarse" con la razón (2007: 47). La vanidad innata no se resigna a aceptar lo verdadero del adversario; ésta, hermanada a la charlatanería y a la también innata improbidad, da como resultado un interés no tanto por tener razón como por aparentar que se tiene. Según señala el filósofo, quien discute no lucha por el amor a la verdad, sino por su tesis, por fas o por nefas (2007: 48).

A lo que habría que añadir con más motivo que quien hace propaganda política o tiene intereses comerciales, como le sucede al autor de nuestra obra, busca una adhesión inmediata, aunque esta sea irracional.

Como afirmaron especialistas como Montesinos (1955), Benítez (1979) o Botrel (1974), y queda claro tras lo expuesto, los intereses comerciales están estrechamente vinculados al posicionamiento ideológico de su novela. Como editor y autor, Ayguals se debe al mercado. Si a ello le añadimos la experiencia de la guerra, el odio hacia los carlistas y el clero, acrecentado tras la muerte de su hermano, su innata vanidad -señalada por Benítez, y clara para el lector-, así como su dedicación política y pertenencia a un grupo ideológicamente minoritario, todo conduce al novelista a la utilización de estratagemas erísticas en aras de aparentar tener la razón. 
CuandoSchopenhauer escribió su Dialéctica erística (en 1830 o 1831, aunque publicada póstumamente), dijo haberse propuesto recoger las "astucias, ardides y bajezas" a las que se recurre con el propósito de obtener la victoria dialéctica. En Parerga y Paralipómena señala cómo son tan frecuentes estas estratagemas que es fácil identificarlas, es decir, su labor es de identificación de un fenómeno existente, en que su práctica preceda a la teoría, por lo que añade incluso "las paradas correspondientes a cada ataque" (2008: 27-28). Así, distingue entre figuras dialéctico-erísticas y figuras retóricas, siendo las primeras un complemento de las otras. Esas 38 argucias y subterfugios componen "el arte de tener siempre la razón", o más bien, de aparentar tenerla, al margen de que sea o no verdad la tesis. Es decir, el filósofo de la primera mitad del siglo XIX, percibe en la dialéctica del momento estrategias eficaces en la consecución del objetivo persuasivo, sin que por ello sea veraz, intelectualmente lícito o convincente para todo receptor aquello que se dice. A su juicio, la verdad objetiva hay que dejársela a la lógica y a la dialéctica, el arte de tener razón. Contrariando a Aristóteles, considera que erística y sofística no deben separarse, ya que esa diferencia "se refiere a la verdad material objetiva sobre la que no podemos tener previamente algo claro" (Schopenhauer, 2008: $50)$.

La novela de Ayguals, como prometió en sus primeras páginas, está llena de "todo recurso necesario" para propagar su ideología (y publicitar su producto). La enorme extensión de la novela y su enrevesada trama nos proporcionan numerosos episodios histórico-novelísticos cuyo análisis muestra la astucia del autor. Sin embargo, la extensión nos obliga a escoger algún ejemplo que, por ser pilar del argumento y semejante en estratagemas a los demás, resulta concluyente.

María se inicia con la matanza de religiosos del 17 de julio de 1834 bajo el gobierno liberal de Martínez de la Rosa. La Historia cuenta que hordas populares creyeron el bulo, hecho correr por la masonería, de que los frailes habían provocado el cólera envenenando el agua de las fuentes públicas. Una muchedumbre, junto con la participación de los milicianos, comenzaron la matanza de religiosos con 16 jesuitas de la calle de Toledo, a los que despedazaron, luego fueron contra los dominicos de la calle Atocha, a ellos les siguieron los mercedarios de la Plaza del Progreso, los capuchinos y los franciscanos de San Francisco el Grande, donde otros 52 frailes fueron víctimas (Menéndez Pelayo, 2007: 287-289). Más de setenta religiosos fueron asesinados y sus conventos profanados. Durante ocho o diez horas ininterrumpidas se sucedieron descuartizamientos, asesinatos y saqueos, ante la impasibilidad de las fuerzas del orden: la Milicia Urbana o la tropa de nueve mil militares, pues hasta se cuenta que el capitán general se paseaba a caballo sin intervenir e incluso amonestando a los jesuitas por envenenar las fuentes (Menéndez Pelayo, 2007: 289). Sabemos, por ejemplo que aquel día, en una taberna de la calle Concepción Jerónima se frieron los sesos de un jesuita y otros varios horrendos sucesos de la misma naturaleza (Menéndez Pelayo, 2007: 286). Menéndez Pelayo contaba cómo Martínez de la Rosa -masón de primer grado-, confesó en su lecho de muerte la organización de las logias en aquellos acontecimientos (2007: 286). 
Este punto de arranque histórico de la novela sirve de contrapunto al autor, que quiere propagar la idea de que existía una masonería blanca. El escritor no puede negar la evidencia histórica de la absoluta inocencia del clero en la propagación del cólera, que oficialmente fue reconocida, pero si niega la culpabilidad del pueblo (fueron "unos pocos e indignos españoles", 1847: 53) y la participación de la Milicia Urbana (apelando también a su conocida honorabilidad). Por supuesto, omite cualquier referencia a las logias: la culpa -repetirá- ha sido del Gobierno, por su imprevisión e ineptitud.

El objetivo de Ayguals al exponer el hecho es defender al pueblo, a su adorada Milicia Urbana, a los anticlericales y a los liberales, así como preparar el terreno para acusar al clero de despótico, inquisitorial y perteneciente a una misteriosa sociedad secreta, que retrata como una masonería blanca. Para ello busca responsables en el propio clero y entre los liberales moderados. Con tal fin culpa al Gobierno. Y para tal 'perversión' histórica, se sirve de un elevado número de estrategias erísticas, según la clasificación de Schopenhauer.

No hay espacio para un análisis pormenorizado de las mismas (ni para un análisis de todos los hechos históricos que rentabiliza económica y políticamente), pero como ejemplo, vemos que la afirmación del adversario se lleva más allá de los límites naturales, tomándola en el sentido más general y amplio para llevarla al absurdo evidentemente, no todos los hombres del pueblo estuvieron asesinando frailes. A la vez, la afirmación propia -honradez del pueblo y de la Milicia- se especifica cuanto se pueda: así, nuestro jornalero Anselmo el Arrojado, miliciano del pueblo, se enfrenta a las hordas para salvar al único franciscano que no debió de perecer, y este es el malvado Fray Patricio.

La segunda estratagema también se usa prolijamente a lo largo de toda la novela, pues es el uso de la homonimia para extender el anticlericalismo (el clero es "perverso", "maligno", "malvado", "ambicioso", "poderoso", etc...) y del elogio del pueblo ("honrado", "virtuoso", "leal", "honorable", "laborioso", "trabajador"...). Siguiendo la tercera estratagema en defensa del pueblo y en ofrecimiento del Gobierno como culpable, se formula una afirmación de modo relativo como si fuera en general: Si el gobierno hubiera intervenido frenando la matanza, ésta no se habría producido, nos viene a decir Ayguals. A lo que cabría refutar, que en realidad, lo probable, y no seguro, es que no hubieran sido tantos los asesinatos, ni tan crueles, ni tan numerosas las órdenes atacadas y saqueadas, si bien, no fueron las fuerzas del orden quienes asesinaban.

Hasta llegar a responsabilizar al clero y a los jesuitas de la matanza, como finalmente Ayguals hará, procura ir dosificando premisas, haciendo prosilogismos, enmascarando su tesis hasta que la explicita finalmente, tal y como se recomienda en la estratagema 4. Resumiendo estrategias erísticas, muchas veces emparentadas a las anteriormente citadas, podemos añadir entre las que Ayguals emplea: premisas falsas, preguntas retóricas para deducir la respuesta, inducciones, símiles, engaños, argumentum ad personam, uso de autoridades escogidas para prestigiar la afirmación propia que prolijamente copia en nota a pie de página, que además, a veces sustituye 
el razonamiento por la mención de autoridades o sustituye las razones para influir en el intelecto del lector, por motivos para influir en su voluntad. Esta última, como dice Schopenhauer, "si es practicable hace innecesarias todas las demás", pues si el auditorio posee los mismos intereses, se gana al instante para nuestra opinión, pues "casi siempre tiene más peso una pizca de voluntad que un quintal de juicio y de persuasión" (2007: 79). Por eso, a pesar de lo espeluznante de la matanza, Ayguals se atreve a culpar a las víctimas de lo que les ha sucedido, pues si nadie del pueblo defendía a los frailes obedecía a que "eran los más encarnizados enemigos de su libertad, de su soberanía":

Avezados a dominarle en tiempos del fanatismo y de la inquisición, a poseer inmensos tesoros so capa de pobreza y humildad, a engañar con refinada hipocresía a los incautos, han aspirado siempre, como la antigua Compañía de Jesús, a hacerse señores de la tierra; y todo sistema liberal, todo sistema de progreso en la civilización, de luces y de publicidad, era contrario á sus proyectos egoístas, basados en la preocupación de las masas populares, proyectos inicuos, que solo podían verse realizados á merced de la tenebrosa ignorancia (1847: 54).

Se trata de la fallacia non causae ut causae (estratagema 20), premisa sobre la que construye el resto de la novela. Sin relación ninguna con lo anterior, pero sí para sus propósitos ideológicos, establece la irracional asociación con la labor educativa de los jesuitas: Por eso mismo, además, los jesuitas pretenden apoderarse de la enseñanza para hacer a la juventud "estúpida y fanática". Asunto que, mutatio controversiae (estratagema 18), abandona pronto por no tener relación con la cuestión.

La dialéctica erística es innata, como el propio Schopenhauer afirma: no es necesario el estudio de estratagemas para servirse de ellas, pues quien defiende ardientemente una tesis no busca tener razón, sino lograr la victoria; se trata de quedarse con ella lícita o ilícitamente. En consecuencia, y dado que esta preocupación refleja un contexto ideológico y filosófico en que estas disputas son frecuentes, es lógica la desaprobación pública de quienes, compartiendo buena parte de su postura política, desaprueban los métodos empleados por el folletín, como sucedía con Marx y Engels. Así, en definitiva, no se logra que la literatura se aleje de la "poetización de la realidad", del "imperio etéreo de los sueños" para pasar a "realizar la poesía", como Marx deseaba.

Un golpe brillante -escribe Schopenhauer- es el conocido como retorsio argumenti: dar la vuelta al argumento del adversario y utilizarlo en su contra (estratagema 26). No sólo no se menciona la intervención de las logias en la matanza de frailes, sino que el capítulo siguiente es la descripción de la masonería blanca y de las despóticas ambiciones de sus apostólicos miembros. La Historia hoy nos confirma la implicación de las logias masónicas en estos hechos históricos, por eso, el mejor recurso para Ayguals es aceptar la existencia de sociedades secretas: así, sirviéndose de la leyenda popular sobre el Ángel Exterminador, la describe integrada por clérigos y absolutistas. Un extenso capítulo detalla pormenorizadamente esta sociedad secreta, tomando como modelo la parafernalia masónica, pues apelando a lo conocido y detallándolo se consigue la verosimilitud poética, y así, es más creíble atribuirle crímenes y conspiraciones. Los integrantes de la literaria sociedad el Ángel Exterminador llevan, 
en lugar de mandiles, túnicas procesionarias y ocultan su rostro con misteriosos capirotes, así también, su rito y consignas remedan los masónicos (1847: 111-115), que el escritor conocía en primera persona9.

\title{
5. ¿VICTORIA O FRACASO RETÓRICO?
}

La controversia puede ser muy fructífera para todos los implicados cuando sirve para rectificar, confirmar o añadir motivos, pero para ello, como decía Schopenhauer, los contendientes han de estar al mismo nivel en conocimiento, habilidad e ingenio. En virtud de estas ideas y teniendo en cuenta que Ayguals es un hombre culto que reconoce, como veíamos, que en la palestra pública son otros los victoriosos, se dirige erísticamente a adeptos fanatizados ideológicamente y lectores y oidores analfabetos o analfabetos funcionales. Como en un discurso político, su objetivo no es convencer al adversario, sino multiplicar la adhesión de los ya ideológicamente adeptos y lograr la adhesión y victoria sobre los indecisos (así como lograr engancharlos en la compra de su novela por entregas).

En palabras de Schopenhauer, con una argumentación o contraargumentación mala y ordinaria se puede lograr la victoria a ojos de un auditorio compuesto por ignorantes (2007: 91). En este sentido, cabe analizar si los objetivos marcados por el autor al escribir la novela han logrado el éxito perseguido. Así, hemos de clasificar los objetivos en implícitos -económicos y comerciales- y explícitos -ideológicos. Respecto a los primeros, Ayguals los alcanza rotundamente: la historia de María es internacionalmente conocida en su momento y editada en nuestro país en numerosas ocasiones, incluso medio siglo después de su muerte, cuando en la década de los veinte vuelve a publicarse en dos ocasiones. Ideológicamente, también resulta un éxito, puesto que entusiasma a un público no culto, si bien no logra el reconocimiento artístico, aunque esa es tan sólo una pequeña élite de intelectuales.

El folletín es obra de una persona inteligente y culta que se dirige a un público que mayoritariamente no lo es. Esa es la base erística de la novela de Ayguals, la estratagema que Marx critica de Sue, pues como Schopenhauer explica:

\begin{abstract}
se arguye una observación inválida, cuya invalidez sólo reconoce el experto. Si bien el adversario lo es, no así el auditorio: a sus ojos, nuestro adversario pasará por ser el derrotado, y aún más rotundamente si la observación que se hizo pone en ridículo de algún modo su afirmación. La gente está enseguida dispuesta a la risa; y se obtiene el apoyo de los que ríen (estratagema 28; 2007: 71-2).
\end{abstract}

De ahí la caricaturización de Fray Patricio: gordo, feo, sucio, comilón, dormilón, ambicioso, rijoso... ridículo y risible. De ahí, la descripción pormenorizada de

$9 \quad$ Aunque la fama le precedía, dado que la pertenencia a la masonería sólo se oculta en vida y puede reconocerse de quienes ya han muerto, el nombre de Wenceslao Ayguals de Izco figura públicamente en las listas de integrantes del Gran Oriente, del que formaba parte ya, al menos cuando fue diputado a Cortes, en 1836. Por otro lado, ni siquiera un liberal reconocido como Galdós dará crédito a la leyenda del Ángel Exterminador (Un voluntario realista, 1878). Respecto a la falsedad de la que aquí nos ocupa, remito a los concluyentes trabajos históricos de Arsenal, Sanchiz y Ayuso (2006: 87-90), también en su versión más reciente Arsenal, Sanchiz (2013). 
los grotescos rituales y discursos de los sacerdotes de la ficticia sociedad El Ángel Exterminador: ocultas sus ambiciones en la vestimenta de los penitentes y su rostro en los capirotes, explicitan en sus secretas reuniones su deseo de apuñalar a los liberales y recomiendan fingirse amables, sobre todo con sus víctimas más fáciles: los niños y las viejas. En el discurso iniciático de esta supuesta masonería blanca se dan argumentos especulativos para fomentar el anticlericalismo: “El púlpito y el confesonario son las armas más poderosas para combatir las armas liberales" o "Es más fácil dominar a los reyes que a los pueblos", "Finjamos humildad para humillar al universo" (1847: 113114).

Bajo el análisis retórico-erístico y en función de los objetivos reconocibles en la obra, podemos sintetizar unos objetivos propuestos por el autor en su novela, los recursos retóricos, editoriales o literarios de los que se vale y, siguiendo a Schopenhauer y las apreciaciones de Marx, las "paradas" lógicas que un lector culto encuentra para invalidar sus tesis:

\begin{tabular}{|c|c|c|}
\hline OBJETIVOS & RECURSOS & PARADA \\
\hline $\begin{array}{l}\text { 1- Convencer de la } \\
\text { maldad del clero } \\
\text { y la brutalidad } \\
\text { del "despotismo } \\
\text { teocrático", y } \\
\text { otros opresores } \\
\text { como la } \\
\text { aristocracia. }\end{array}$ & $\begin{array}{l}\text { Inventar un personaje al que } \\
\text { convierte en fraile. } \\
\text { Inventar a una marquesa falsa que } \\
\text { fomenta el vicio entre los ricos y } \\
\text { poderosos. } \\
\text { Ilustrar el texto con grabados } \\
\text { "elocuentes". }\end{array}$ & $\begin{array}{l}\text { Es ficción -no Historia. } \\
\text { El fraile es ficticio, } \\
\text { hiperbólica proyección de } \\
\text { un estereotipo. Además, } \\
\text { Fray Patricio ni siquiera era } \\
\text { fraile, pues fue exclaustrado } \\
\text { al principio de la novela. } \\
\text { Lo mismo sucede con la } \\
\text { Marquesa de Turbiasaguas, } \\
\text { quien tampoco es } \\
\text { aristócrata. En este caso, } \\
\text { otros aristócratas suavizan la } \\
\text { crítica. }\end{array}$ \\
\hline $\begin{array}{lr}\text { 2- } & \text { Persuadir de la } \\
\text { existencia de una } \\
\text { Sociedad Secreta } \\
\text { absolutista y } \\
\text { clerical que } \\
\text { intervenía en los } \\
\text { hechos políticos } \\
\text { e históricos } \\
\text { injusta y } \\
\text { malévolamente. }\end{array}$ & $\begin{array}{l}\text { Apagogé, da por cierta la } \\
\text { leyenda popular de un Ángel } \\
\text { Exterminador, para la que } \\
\text { inventa pormenorizadamente } \\
\text { su aspecto, modos de actuar, sus } \\
\text { rituales, vestimenta y discursos } \\
\text { en sus reuniones, diálogos e } \\
\text { intervenciones en acontecimientos } \\
\text { políticos. Verosimilitud lograda } \\
\text { por el detallismo, el atractivo } \\
\text { misterioso o la mixtura de } \\
\text { elementos inquisitoriales, masones } \\
\text { y conspirativos. } \\
\text { Ilustraciones sugestivas, } \\
\text { misteriosas, detalladas en que se } \\
\text { aúna lo imaginado con lo histórico } \\
\text { y real. }\end{array}$ & $\begin{array}{l}\text {-Es ficción, no se } \\
\text { proporcionan pruebas. } \\
\text { Además, para un lector } \\
\text { competente, formal } \\
\text { y narrativamente es } \\
\text { notorio el contraste entre } \\
\text { aquellos acontecimientos } \\
\text { basados en la Historia, } \\
\text { que el autor acompaña de } \\
\text { documentación, y estas otras } \\
\text { páginas salidas totalmente } \\
\text { de su imaginación que } \\
\text { carecen de rigor histórico. }\end{array}$ \\
\hline
\end{tabular}




\begin{tabular}{|c|c|c|}
\hline 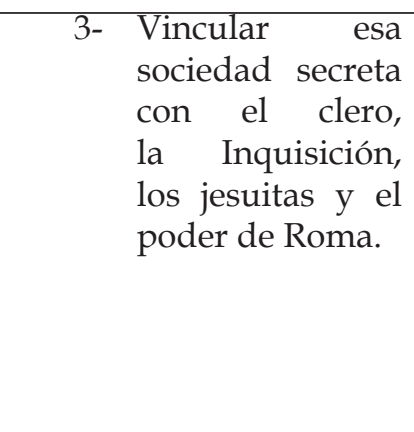 & $\begin{array}{l}\text {-En descripciones realistas, } \\
\text { entrevera estas ideas y hace crítica } \\
\text { del pasado de la Inquisición, de la } \\
\text { Compañía de Jesús y enumera los } \\
\text { males acarreados que les atribuye. } \\
\text {-Se recurre al temor, a la leyenda y } \\
\text { al sentimentalismo. } \\
\text {-Se toma erísticamente lo no } \\
\text { fundamentado por el fundamento } \\
\text { (fallacia non causae ut causae) }\end{array}$ & $\begin{array}{l}\text {-Es ficción y pura } \\
\text { especulación, se repite el } \\
\text { llamativo contraste entre lo } \\
\text { material y lo especulativo, } \\
\text { ningún dato lo avala. } \\
\text { Fray Patricio ni es fraile } \\
\text { ni es jesuita -había sido } \\
\text { franciscano. }\end{array}$ \\
\hline $\begin{array}{l}\text { 4-Responsabilizar de las } \\
\text { desavenencias y fracasos } \\
\text { liberales al Ángel } \\
\text { Exterminador. }\end{array}$ & $\begin{array}{l}\text {-Da como argumento la } \\
\text { afirmación de la imposibilidad } \\
\text { de otra causa. Las desavenencias } \\
\text { internas de los liberales y su mala } \\
\text { actuación en casos que relata, han } \\
\text { de ser fruto de estas intrigas por } \\
\text { que sí, como única explicación } \\
\text { posible, sin dato alguno o prueba. } \\
\text { Estratagema erística dando a } \\
\text { elegir entre una tesis y su opuesta, } \\
\text { de modo que la tesis más probable } \\
\text { parecerá en comparación cierta } \\
\text { (¿Qué otra explicación habría } \\
\text { para que los liberales actuasen } \\
\text { contrariando la libertad?) }\end{array}$ & $\begin{array}{l}\text {-Ficción y especulación. Se } \\
\text { apela esencialmente a un } \\
\text { deseo, por ello, irracional e } \\
\text { indemostrable, pero eficaz } \\
\text { en un destinatario popular. }\end{array}$ \\
\hline $\begin{array}{l}5 \text {-Proponer reformas } \\
\text { sociales. }\end{array}$ & $\begin{array}{l}\text {-Proporciona datos concretos, } \\
\text { cifras exactas, fuentes fiables } \\
\text { y prestigiosas -discursos } \\
\text { parlamentarios, noticias } \\
\text { recogidas por la prensa, autores } \\
\text { y obras especializados con datos } \\
\text { bibliográficos. }\end{array}$ & $\begin{array}{l}\text {-Sus "propuestas" son } \\
\text { copia de las leídas muchas } \\
\text { veces en Sue, al que cita, } \\
\text { y otras "propone" lo que } \\
\text { reconoce en nota que ya } \\
\text { existe: sociedades gremiales, } \\
\text { sociedades para jóvenes, } \\
\text { para mujeres, reformas del } \\
\text { sistema penitenciario, cajas } \\
\text { de ahorro... Aunque no son } \\
\text { novedad, argumenta, apoya } \\
\text { y divulga estas realidades } \\
\text { aún incipientes. } \\
\text { Se deja arrastrar por } \\
\text { la vanidad, lastrando } \\
\text { enormemente el relato en } \\
\text { torpes "incrustaciones" } \\
\text { políticas. }\end{array}$ \\
\hline 6- Vender & $\begin{array}{l}\text {-Agasaja al lector-comprador, } \\
\text { le proporciona un culpable } \\
\text { a todos sus males, recurre al } \\
\text { sentimentalismo, populismo, } \\
\text { patetismo, idealismo... y lo } \\
\text { acompaña de datos seleccionados } \\
\text { a tal fin, objetivos e históricos, } \\
\text { entreverados con los subjetivos y } \\
\text { ficcionales. }\end{array}$ & $\begin{array}{l}\text {-Inapelable: aunque hoy } \\
\text { en día no venda, tiene el } \\
\text { privilegio de que muchas } \\
\text { de sus obras son de acceso } \\
\text { libre a través de internet. Su } \\
\text { retórica persiste en medios } \\
\text { populares, cada vez más } \\
\text { masivos y dominantes }\end{array}$ \\
\hline
\end{tabular}


Aunque el juicio literario y artístico hayan de condenarlo a la hoguera cervantina, Ayguals obtiene una sonadísima victoria: "Capitalista" contemporáneo, nada más lejos de la premisa del arte por el arte, adapta la máxima de enseñar deleitando a un contexto comercial, social y político nuevo para seguir un nuevo objetivo: adoctrinar y vender deleitando. En ese sentido, es indudable que logra con una eficacia nunca antes vista en nuestro país, algo enormemente codiciado hoy en día: su gran logro es convertir la propaganda política en un producto comercial y en un gran éxito de ventas.

\section{BibLIOGRAFÍA}

Anónimo (1846): De la Novela-Folletín. Su origen, progresos e influencia social, Madrid, Sociedad Tipográfica de Hortelano y compañía.

Aubert, P. (2005): “Crisis del papel y consecuencias de la industrialización de la prensa (1902-1931)", en J.M. Desvois (coord.) (2005), Prensa, impresos, lectura en el mundo hispánico contemporáneo: Homenaje a Jean-François Botrel, Bordeaux, Presses Universitaires de Bordeaux, 73-96.

Araque, B. M. (1851): Biografía del señor D. Wenceslao Ayguals de Izco, Madrid, Imprenta de La Sociedad Literaria.

Arsenal, L., Sanchiz Álvarez de Toledo, H. y Ayuso, P. (2006): Una historia de las sociedades secretas españolas, Barcelona, Planeta.

Arsenal, L. y Sanchiz Álvarez de Toledo, H. (2013): Historia de las sociedades secretas españolas (1500-1936), Madrid: Sepha.

Ayguals de Izco, W. ([1845-1846], 1847): María, la hija de un jornalero, Madrid, Imprenta de D. Wenceslao Ayguals de Izco.

Baroja, P. (2008): Memorias de un hombre de acción, tomo II. Madrid, Biblioteca Castro.

Baulo, S. (2005): "Prensa y publicidad en el siglo XIX: El caso de la Sociedad Literaria de Madrid (1845-1846)", en J.M. Desvois (coord.) (2005), Prensa, impresos, lectura en el mundo hispánico contemporáneo. Homenaje a Jean-François Botrel, Bordeaux, Presses Universitaires de Bordeaux: 61-71.

Benítez, R. (1979): Ideología del folletín español: Wenceslao Ayguals de Izco (1801-1873), Madrid, José Porrúa Turanzas.

Botrel, J-F. (1974): “La novela por entregas, unidad de creación y de consumo” en Botrel y Salaün (eds.), Creación y público en la literatura española, Madrid, Castalia: 111-115.

Botrel, J-F. (1998): “Teoría y práctica de la lectura en el siglo XIX: el arte de leer", Bulletin Hispanique, vol. 100, n II: 577-590.

Calvo Carilla, J. L. (2008): El sueño sostenible: Estudios sobre la utopía sostenible en España. Madrid: Marcial Pons. 
Fernández Montesinos, J. ([1955], 1980): Introducción a una historia de la novela en España, en el siglo XIX, Madrid, Castalia.

Hesiodo (1990): Trabajos y días, en Teogonía, Trabajos y días, Escudo, Certamen, Madrid: Alianza Ed.

Hortelano, B. (1936): Memorias, Madrid, Espasa-Calpe.

Lukács, G. (1976): La novela histórica, Barcelona, Grijalbo.

Marx, K. y Engels, F. (1981): La sagrada familia, Madrid, Akal.

Menéndez Pelayo, M. (2007): La historia de España, Madrid, Ciudadela.

Reyero, C. (2008): “Gusto y libertad. El arte en la novela María, la hija de un jornalero de Ayguals de Izco", Anales de Historia del Arte, N Extra.: 475-488.

Romero Tobar, L. (1998): “La génesis del Realismo y la novela de tesis", en V. García de la Concha (dir.) (1998) Historia de la Literatura Española. El siglo XIX, II, Madrid, Espasa Calpe: 410-435.

Sánchez García, R. (2001): “Las formas del libro. Textos, imágenes y formatos”, en J. Martínez Martín (dir.) (2001) Historia de la edición en España, 1836-1936, Madrid, Marcial Pons: 111-133.

Schopenhauer, A. (2007): Dialéctica erística o El arte de tener razón, expuesta en 38 estratagemas, L.F. Moreno Claros (trad. e intr.), Madrid, Editorial Trotta.

Schopenhauer, A. (2009): Parerga y paralipómena. Escritos filosóficos sobre diversos temas, J. R. Hernández (ed.), J. R. Hernández, L. F. Moreno y A. Izquierdo (trads.), Madrid, Valdemar. 